International Journal of Instruction e-ISSN: 1308-1470 • www.e-iji.net
April 2019 • Vol.12, No.2

p-ISSN: 1694-609X

pp. 539-558

Received: 25/09/2018

Revision: 03/02/2019

Accepted: $12 / 02 / 2019$

OnlineFirst: 17/03/2019

\title{
Analyzing Discourses of Gifted Students in Terms of Their Perspectives on Social Gender
}

\section{Dilek Ünveren Kapanadze}

Asst. Prof., Süleyman Demirel University, Faculty of Education, Turkish Education, dilekkapanadze@sdu.edu.tr

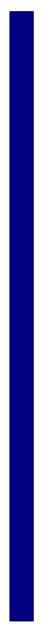

This study aims to investigate the perspectives of gifted students on social gender through the stories they wrote and personal identification forms. In the study, cross-sectional screening method was used. The sample of the study was 55 gifted students of Centre of Science, Art and Education in 6 provinces of Turkey. Content analysis and Pearson Product-Moment Correlation Coefficient were used to analyze data. Items in the texts were examined in their relation to each other. Not only the frequency analysis was made, also we tried to identify and analyze the context and positions of the items in relation to others. As result of content analysis, we concluded with seven categories; linguistic form, language code, grammar structure and features, vocabulary specificity, ambiguity and uncertainty and power of attitude. In the structures related to linguistic form, intensely female or intensely male expressions and semantic constructs that connate them were observed. The traditional and common way of using and attaching meaning to the words, were found in many stories. Some students employed the words in the context of traditional social values and the taboo gendered discourse, while others used them to produce opposing discourse.

Keywords: gendered discourse, gifted students, language, education, story writing

\section{INTRODUCTION}

This study emerged from issues and discussions about tight junction and relationship between education, language and power in everyday conversations, studies and social practices in the areas of language, gender and studies on them (Levon \& Mendes 2016; Milani 2015; Cameron \& Kulick 2006; Gee 2008; Florio-Ruane \& Morrell 2012). Schools, learning and teaching practices are often regarded as neutral in terms of gender issues. Language teaching often emphasizes linguistic proficiency and basic communicative skills over meaning making and creating processes. This kind of approach overlooks the discursive aspects and functions of language practices. More specifically, this study tries to understand whether and how language used and meaning created in especially first language classrooms to produce, reproduce and maintain a

Citation: Ünveren Kapanadze, D.. (2019). Hybrid-PjBL: Analysing Discourses of Gifted Students in Terms of Their Perspectives on Social Gender. International Journal of Instruction, 12(2), 539-558. https://doi.org/10.29333/iji.2019.12234a 
gendered discourse of society, and how this is reflected on the discourses and products of students and learning environment. In this context, as discourse analysis suggests, our analysis not only focuses on what was said but also what was not said, and their relationship with each other (Cameron \& Kulick 2003; Kulick 2006). Thus, the presence and absence of women in the discourses of students, or absence of some qualifiers in respect to women, give also clues and regarded as important findings in our search for the perspectives of the students on gender issues, social gender roles and descriptions. Identity construction through education in family and schools, is a dynamic process that includes active linguistic choices from a range of resources (Holmes \& Marra, 2010) that can be reflected on students' oral and written products and their discussions some of which are indexed for gender (Ochs, 1992). In our study, what we have tried to do is identifying the ways in which gender identity and gendered discourse constructed and reflected through language which requires paying careful attention to many and diverse linguistic and discursive resources and individual styles which frame and show the perspectives of the producers and users of language, in our case the writers of stories; participants of the study.

According to Bourdieu, the education systems in different kinds of societies and cultures function in such a way to legitimize accepted values, norms and class inequalities; therefore, for Bourdieu, educational credentials help to reproduce and legitimate social norms and inequalities (Sullivan, 2002), as dominant and prevailing ideas and culture holds its power and place in the social structure, these inequalities can be across classes and genders. French sociologist Pierre Bourdieu (1930-2002), developed the concepts of habitus and cultural capital to explain the ways in which relationships of social norms and structure were reproduced through the education system. Cultural capital that exists in two forms: as a disposition of the mind, objectified as cultural goods and in the institutionalized state as educational qualifications. Students may come to the classroom with an already existing disposition and perceptions about gender issues, and it takes shapes through education and school. Schools are instruments for the reproduction of family acquired habitus that certifies the dominant cultural code of society. Habitus, in Bourdieu's studies, is a system of embodied dispositions and practices in accordance with the structural principles of social world or society (Nash, 1990). However, sometimes it is developed in a different way than their acquired values or cultural capital that their families present to and/or impose on them. In this study, by 'socially constructed or gendered discourse styles', we mean that ways of speaking and use of language are not innate factors; they are learned and developed through socialization and interaction in various social groups (Lakoff, 1975; Tannen, 1994; Bakhtin, 1981; Sullivan et al., 2015). According to Bandura (1977) values can be taught or acquired through observation. That means child's perception may be developed by adults by observing their behaviour, or can be effected in undesirable way. In social learning theory, child pays attention to the remarkable properties of their role models such as their teacher, parents, heroes or film characters. These features can be community, society or culture-approved examples as well as examples of cause of erosion in community structure (Altıntaş, 2016). Therefore, it is very important what is aimed, fulfilled and neglected in educational process which is one of the most valuable social 
environments to learn socially and to become good role models. In this context, the stories written by the participants and personal identification forms were examined whether gendered discourse styles and ideas were evidenced; and whether some of factors on identification forms effected the production of that kind of discourses. In this sense, through this study, answers for the following questions were sought:

1. Is there any relationship between genders of participants and their tendency towards attaining meaning to gender roles?

2. Is there a sexist approach in the discourses and the languages of the stories? If so, in what way does it tend to occur?

3. Do variables such as environment, socio-economic and education status of the participants' parents have effect on sexism and perspectives of participants?

\section{METHOD}

\section{Research Design}

In this descriptive study, cross-sectional screening method was used. In cross-sectional surveys, the data collection process is carried out once in a while (Fraenkel \& Wallen, 2000) and the characteristics of the examined study are described as they exist (Özdemir, 2014). In this study, the data collecting process was carried out once and the students' viewpoints on sexism were analyzed in terms of various variables as they existed in the data. The sample of the study was composed of 55 gifted students of SAEC (Science, Art and Education Center) in 6 provinces of Turkey; Isparta, İstanbul, Konya, Adana, Samsun, Malatya. The stories which were written by students to identify their discourses; and personal identification forms which gave way to evaluate the study in terms of various variables were used as data collection tools. In sum; for the $1^{\text {st }}$ and $3^{\text {rd }}$ research problem; that is, identifying the relationship between personal and social identities of the participants, and their perspectives on and tendency towards attaining meaning to gender roles, we used both the socio-demographic information on personal identification forms developed by the researcher and stories as products created by students. In order to collect data for the $2^{\text {nd }}$ research question, we analyzed texts/stories written by students. 40 key words were presented to students that at least 10 of them would be used during writing stories, we analyzed the use of words by their meanings attached by students.

\section{Participants}

Sample can be defined as the units or group of elements selected by any method appropriate to the purpose of the study from the research universe and capable of representing the universe (Çil, 2005). The sample of the study were selected in line with the cross-sectional screening method in this study, and a total of 55 students from Science and Art Center (BİLSEM) of the provinces; Adana, İstanbul, Malatya, Sivas, Konya, Isparta, who volunteered to participate in the study. Since the issue is on social gender perspective, premises of the developmental psychology's personality development and cognitive development areas were taken into consideration in deciding on the sample. In addition, the aim of the study and the variables included in the 
identification forms also effected while selecting the sample. In the analysis of the data, it was aimed that the results obtained from the sample could represent the universe and therefore, the expert was again consulted when identifying the sample.

\section{Data Collection}

\section{Qualitative Data Collection}

The texts obtained as a result of writing stories by using the words given to them in order to reveal the gender perspective of gifted students, both created the focus of the study and enabled the acquisition of qualitative data. While determining the words that will be the source of the research, the researches on the subject, the researches on gender sociology, the academic and professional literature were reviewed, and the articles in reputable journals were also examined. By also consulting the experts in this area, this data was arranged to include the variables that could be used in the analyses. In this sense, since it was aimed to reveal the relationships between variables, to make predictions and to correlate the variables; attention had also been paid to the fact that they were valid structures that would be the source of quantitative data analysis.

\section{Quantitative Data Collection}

An identification form was created to generate quantitative data. In identification forms, the parental education status, the position of the parent in the working life, the gender of the participants, the number of siblings, the presence and absence of the study room etc. were included. In addition to these structures that took place in the identification forms, theses, projects, monographs and scales about gender perception were examined and these elements were also included in the forms. In the context of the relationship between the aim of the study, the research question and the approach on the topic of the study, the data was used in descriptive statistics such as average and percentage. In the stories produced by the students by using the given words, since the continuity of the relationship between the words chosen and used by the students that have gender references and the variables was sought, these used in such a way as to give opportunity to obtain quantitative data, and in this respect the stories written by students and the words chosen by them were rearranged to include variables that could be tested and used in the analyses. In this sense, it is aimed to reveal the relationships between variables, make predictions and associate variables.

\section{Data Analysis}

In this study, since both quantitative and qualitative data collected, to analyze these different of kinds data, accordingly different kinds of data analysis methods used. In the analysis of the data, since the data showed a normal distribution, a parametric test; Pearson Moment-Production Correlation Coefficient was used. This method of parametric analysis is used in studies aimed at determining whether there is a relationship between two variables and to identify the relationship (Seçer, 2017). It was aimed to obtain information about the power and direction of the relationship between variables through correlation analysis. In our study, this correlation coefficient was used to determine the linear relationship between the words used and the users of them. 
In correlation analysis, if the data are smaller than 0.05 , which is significance value, that means the relationship between two variables is significant; if they are bigger than 0.05 , that indicates the relationship is not significant. Thus, 0.05 (2-tailed) to 0.01 (2-tailed) intervals were considered to determine whether there was a meaningful relationship, and the coefficient and direction of the relationship; so it was stated that there was a strong meaningful relationship for the ones close to 0,01 and less meaningful relation for the ones close to 0,05 . Therefore, the equivalence between the continuous variables used in similar studies in gender studies was put forward and since the analysis was based on the similar applications; reliability of the study was tested. In this context, the relationship between the words given and the variables was reflected on the analysis. Instead of just examining items one by one, the relationship between the items were also investigated and analyzed. In order to conduct a meaningful analysis, not only the frequency analysis was taken into account, but also we identified and analyzed the context and which item was seen together with which one or ones in addition to looking at the number of appearance of items.

Additionally, content analysis was conducted on the collected data through stories written by the participants. Content analysis can be defined as a set of methodological tools and techniques applied to a wide range of discourses. These tools and techniques, which are considered under the name of content analysis, can be described above all as a controlled interpretation effort and a reading tool based on deduction. This reading is based on the principle of analyzing discourse examples whose boundaries have been already set (Bilgin, 2014). The reliability of the content analysis was ensured by using intercoder reliability. The inter-encoder reliability, also known as intercoder agreement, is that independent coders achieve a common vision and perspective if they encode and evaluate by using the same set of data. The most basic point of this technique is that whether coders of the same data can identify and evaluate the same in a similar way or not (Miles \& Huberman, 1994). For this study, we used the formula below to test the reliability of data analysis:

Reliability $=$ number of agreements $/$ number of agreements + disagreements x 100 (Miles \& Huberman, 1994).

According to this formula, reliability between the coders was found $88 \%$ for coding and determining codes, categories and themes. In this sense, by using the code value of the words given, we found 5 categories under the theme of Language Competency; which are; linguistic form, language code, grammar structure and properties, vocabulary specificity, ambiguity and vagueness. And under the theme of Attitude and Competence; we found 2 categories as power of attitude and other. It was aimed to provide a commentary based on the content, which was meant to be expressed and defined in the messages through the content analysis.

\section{FINDINGS}

\section{Pearson Product-Moment Correlation Coefficient Analysis Findings}

In the correlation analysis, the symbol of the correlation is ' $r$ '. The relationship between two variables can be between +1 and -1 in correlation analysis. If two variables are 
increasing or decreasing at the same time and in the same direction, this is called positive relation. In other cases, it may be the opposite, so increasing one of the variables may cause the other to decrease. In this case; it is called negative relationship in correlation analysis (Seçer, 2017; Kilmen, 2015).

When examining any correlation table, the table is considered in two dimensions. In the first part of the table, the results obtained are showed when the variable whose effect is tried to be controlled is not included in an analysis process and in the second part, the results obtained, when control variable is included in the analysis are shown. In addition, the section which is 'Pearson Correlation' shows correlation coefficient, sig. (2-tailed) denotes 'significance value' and $\mathrm{N}$ indicates the number of participants.

In our study; participants were asked to select at least 10 out of 40 words given and to write a story by using them. In the light of discourses of students, statistically significant metric data on sexist viewpoints and perceptions were analysed by correlation method. Relationship analysis was conducted in the context of the words given, thus, the relationship between genders and gender perceptions of participants was tried to identify and determine whether there was a descriptive relationship between the two. Correlational values of the words given were investigated by selecting commonly accepted words in gender roles researches among the words given to them to write stories. The other words given were used as subscales in this relationship analysis and were not included in the tables below.

Table 1

Social Gender Perspectives of Male Participants

\begin{tabular}{|c|c|c|c|c|c|c|c|}
\hline & & gender & power & blue & Manly & like a boy & breadwinner \\
\hline \multirow[t]{3}{*}{ gender } & Pearson Correlation & 1 & $.380^{*}$ & $.522^{* *}$ & $1.000^{* *+}$ & .208 & $.860^{* *}$ \\
\hline & Sig. (2-tailed) & & .016 & .001 & .000 & .199 & .000 \\
\hline & $\mathrm{N}$ & 40 & 40 & 40 & 40 & 40 & 40 \\
\hline \multirow[t]{3}{*}{ Power } & Pearson Correlation & $.380^{*}$ & 1 & $.728^{* *}$ & $.380^{*}$ & $.546^{* *}$ & $.442^{* *}$ \\
\hline & Sig. (2-tailed) & .016 & & .000 & .016 & .000 & .004 \\
\hline & $\mathrm{N}$ & 40 & 40 & 40 & 40 & 40 & 40 \\
\hline \multirow[t]{3}{*}{ Blue } & Pearson Correlation & $.522^{* *}$ & $.728^{* *}$ & 1 & $.522^{* *}$ & $.397^{*}$ & $.607^{* *}$ \\
\hline & Sig. (2-tailed) & .001 & .000 & & .001 & .011 & .000 \\
\hline & $\mathrm{N}$ & 40 & 40 & 40 & 40 & 40 & 40 \\
\hline \multirow[t]{3}{*}{ Manly } & Pearson Correlation & $1.000^{* *}$ & $.380^{*}$ & $.522^{* * *}$ & 1 & .208 & $.860^{* *}$ \\
\hline & Sig. (2-tailed) & .000 & .016 & .001 & & .199 & .000 \\
\hline & $\mathrm{N}$ & 40 & 40 & 40 & 40 & 40 & 40 \\
\hline \multirow[t]{3}{*}{ like a boy } & Pearson Correlation & .208 & $.546^{* *}$ & $.397^{*}$ & .208 & 1 & ,241 \\
\hline & Sig. (2-tailed) & .199 & .000 & .011 & .199 & &, 134 \\
\hline & $\mathrm{N}$ & 40 & 40 & 40 & 40 & 40 & 40 \\
\hline \multirow[t]{3}{*}{ breadwinner } & Pearson Correlation & $.860^{* *}$ & $.442^{* *}$ & $.607^{* *}$ & $.860^{* *}$ & .241 & 1 \\
\hline & Sig. (2-tailed) & .000 & .004 & .000 & .000 & .134 & \\
\hline & $\mathrm{N}$ & 40 & 40 & 40 & 40 & 40 & 40 \\
\hline
\end{tabular}

The relationship between the use of words and phrases like; 'gender, power, blue, manly, like a boy and breadwinner, which were determined as gender and gender perception towards men was shown in table 1 and the relationship were explained as: Among the words used towards males in the context of sexism, a positive meaningful relationship was found between the words as 'gender and power' ( $1 / .380 ; \mathrm{r}=380)$; 'blue and manly' 
$(1 / .522 ; \mathrm{r}=522)$; 'like a boy and manly' (1/.208; r=208); 'like a boy and breadwinner $(1 / .241 ; \mathrm{r}=241)$. In this sense, it was seen in the data analysed that there was a meaningful relationship between the words, which were commonly accepted by the context of masculine discourse and used by male participants and their attached values; and gender role and perspective of the user. Moreover, they used the word 'manly' as an adverb to describe/qualify actions which are done 'properly, decently'. In addition to this, they used the phrase 'like a boy', as a qualifier with similar meaning like; 'as men/boys do, properly, in proper way' etc. 'Breadwinner' was used to describe man as feeding the family and also ruling the house.

Table 2

Social Gender Perspectives of Female Participants

\begin{tabular}{|c|c|c|c|c|c|c|c|}
\hline & & gender & pink & job/task/work & meal & beauty & vulnerable \\
\hline \multirow[t]{3}{*}{ Gender } & Pearson Correlation & 1 & $-.464^{* * 3}$ & $.522^{* *}$ & $-1.000^{* *}$ & $-.596^{* *}$ & $-.369^{*}$ \\
\hline & Sig. (2-tailed) & & .003 & .001 & .000 & .000 & .019 \\
\hline & $\mathrm{N}$ & 40 & 40 & 40 & 40 & 40 & 40 \\
\hline \multirow[t]{3}{*}{ Pink } & Pearson Correlation & $-.464^{* *}$ & 1 & -.243 & $.464^{* *}$ & -.226 & -.140 \\
\hline & Sig. (2-tailed) & .003 & & .132 & .003 & .160 & .389 \\
\hline & $\mathrm{N}$ & 40 & 40 & 40 & 40 & 40 & 40 \\
\hline \multirow[t]{3}{*}{ Job } & Pearson Correlation & $.522^{* *}$ & -.243 & 1 & $-.522^{* *}$ & -.311 & -.192 \\
\hline & Sig. (2-tailed) & .001 & .132 & & .001 & .051 & .234 \\
\hline & $\mathrm{N}$ & 40 & 40 & 40 & 40 & 40 & 40 \\
\hline \multirow[t]{3}{*}{ Meal } & Pearson Correlation & $-1.000^{* *}$ & $.464^{* *}$ & $-.522^{* *}$ & 1 & $.596^{* *}$ & $.369^{*}$ \\
\hline & Sig. (2-tailed) &, 000 & .003 & .001 & & .000 & .019 \\
\hline & $\mathrm{N}$ & 40 & 40 & 40 & 40 & 40 & 40 \\
\hline \multirow[t]{3}{*}{ Beauty } & Pearson Correlation & $-.596^{* *}$ & -.226 & -.311 & $.596^{* *}$ & 1 & $.619^{* * *}$ \\
\hline & Sig. (2-tailed) & .000 & .160 & .051 & .000 & & .000 \\
\hline & $\mathrm{N}$ & 40 & 40 & 40 & 40 & 40 & 40 \\
\hline \multirow[t]{3}{*}{ Vulnerable } & Pearson Correlation & $-.369^{*}$ & -.140 & -.192 & $.369^{*}$ & $.619^{* *}$ & 1 \\
\hline & Sig. (2-tailed) & .019 & .389 & .234 & .019 & .000 & \\
\hline & $\mathrm{N}$ & 40 & 40 & 40 & 40 & 40 & 40 \\
\hline
\end{tabular}

**. Correlation is significant at the 0.01 level (2-tailed).

*. Correlation is significant at the 0.05 level (2-tailed).

The same relationship analysis conducted; in this case for the words and phrases that were used by female participants and were accepted as referring to women, rather than masculine rhetoric by taking selected words into consideration. So, we looked at the relationship between these words and values attached to them; and gender and perception of the user (female). We tried to understand whether the words under discussion were used in accordance with social gender roles of the participants. Thus, following conclusion was reached at: There was a negative meaningful relationship between 'gender and pink' (1 / -.464; r=464); 'gender and work' (1/-.522; r=-522); beauty and meal $(1 /-.596 ; \mathrm{r}=596)$; and positive meaningful relationship between food and pink $(1 / .464 ; \mathrm{r}=464)$, vulnerable and beauty $(1 / .619 ; \mathrm{r}=619)$. Therefore, in the light of table 2, we can conclude that a meaningful relationship between genders and gender perceptions of the participants was found. In this sense, they used the words of; gender, pink, work, meal, beauty and vulnerable in a way that conforms to their gender roles. As a result of relationship analysis, it was observed that the students, who created stories, 
used the specified words in accordance with and in the context of their gender roles. These words, which emphasize male or female references in society, were found in texts and used by participants in accordance with their gender roles and expectations in the society and culture. This finding also was reflected on the analysis of whether there was a descriptive relationship, so same findings of relationship analysis were reached at through descriptive and correlational relationship analyses

\section{Content Analysis Findings}

\section{Linguistic Form}

It is one of the most well-known research topics that language usage patterns were affected by various variables like gender. Many factors, especially gender, cause the same group to use different vocabulary in a same language. In this context, the use of typical female or typical masculine language in the words chosen by the gifted students in their stories, were identified. Although they shared the same language structure, their vocabulary was differentiated in line with their own gender, and this was reflected and observed in the stories. Especially words such as man, manager, boss, strong, courage, being a man of his word, keep his promises, breadwinner, violence etc. are expressed in the use of masculine language while words such as meal, beauty, gender, victim, dinner, fear, equality etc. are expressed in a frame of meaning outside the masculine use of language, or to refer to women. Some examples for such kind of usages are as follows:

Example 1: "Finally, the father came home, the children were so happy. Their mother, had prepared the table and waited for their father to eat." [from the story of 'Home Life' (Ist-2)]

Example 2: "Their father was honest, strong as a real man who was keeping his promises all the time. Mother was very beautiful and everyone admired her beauty." [from the story of "Home Life'(Ist-2)]

Language is a reflection of culture and form of thought of a society, but it does not just reflect that thought, it creates, develops and shapes it. In this sense, the texts also contain attitudes developed against selected masculine discourses and have been expressed by using some kind of paralinguistic function and language facilities/opportunities. Such a situation was observed in the stories of participants, a quotation from one of them 'Equality (Isp-8)' was as follows:

"Her older brother was very opposed to Pembe, who said that gender discrimination should not be done .... For example, there is something like 'making a man's promise', that means making promises. So why dont we say just 'making promises or promising'? This is also a gender discrimination, give up these traditions!"

At the imaginary level, the use of language can change by cultural ideals of maleness and femaleness. It has also been reflected and observed in the stories that the female or male sub-identities were revealed in different way of thinking than in socio-cultural context, such as Cartesian way of thinking like; public or private, traditional or modern. This situation also manifests itself as an element of criticism in the stories. The writer expresses, in this sense, his/her thoughts through the stories s/he created by using the selected words, and s/he knows well to what their stories would refer and what kind of 
effect these texts create. In other words, they are aware of the fact that their texts have some sexist ideas or gendered discourses, and they creating them with a full awareness of their own and society's reality and their own roles as being part of a specific gender. These conscious choices and the way of thinking bring with it a critical discourse. In one of the stories, this situation was expressed as follows:

Example 3: "... I would see the boss for the first time. When I went into the room, I came across with a woman! And at that moment I saw my entire life flash before my eyes and I began to cry ... The founding boss stood up and hugged me with a mother's compassion." (ISP-4)

As shown above, she was so surprised and fall into tears, since she (narrator/writer) did not expected a female boss, a lady to meet her.

The same story continues as follows; "... I immediately raised my head and wiped my eyes, the boss began to tell me that her family had tried hard to prevent her from going to school. According to tradition and customs (!), it was not possible for girls to study. Like me, she had tried hard to convince her family and finished the school." (ISP-4)

As can be seen, the (female) participant created an opposing discourse towards customs and the social reality by using exclamation mark in parentheses after the word of customs: "according to customs (!)". Through this kind of ironic, cynic, sarcastic and contemptuous use of language and conscious choices, she manifests a critical stance towards beliefs, attitudes and customs that put women in a disadvantaged situation. The same applies to the following item, example 5. Even though it has been found in the mind of narrator in its traditional structure, gender roles have been able to put forward with a corrective critical view with an awareness of the need to correct the existing negative situation.

Example 5: “... when everyone was doing a part of a job to prepare the table, he had said: 'Cooking and preparing table are one of the tasks of women.' and he did not do anything. However, now he regrets saying and behaving so. He decided to apologize to his entire family. Yes, he would apologize to his entire family at dinner this evening." (MLT-1)

Example 6: "The householder shouted:"Dinner is ready! "It (the householder, breadwinner) was the mother! She gathered the family council and told all customs in a detailed way." (MLT-4)

Masculine sexist phrases as 'breadwinner, man of the house, and householder' were chosen and used consciously by the writer with a phrase just like an 'annotation': "it was the mother" But here again, through a sexist point of view, this expression is taken from the fact that it is a phenomenon that suggests/reminds/evokes men. In this sense, a world of attitudes and meanings was constructed during the process of forming language through combining the sociological and historical position of women and men with value judgments.

In this context, gender variable has influenced the use of language; and the selecting and using the words in texts have revealed a perspective about gender issues. In addition, criticism of sexism has become another phenomenon observed in the discourses of the participants: 
Example 7: Narrator: "For example, there is something like 'making a man's promise', that means making promises. So why dont we say just 'making promises or promising'? This is also a gender discrimination, give up these traditions! Give up these traditions!"

Caner (male name): You're right, people make a lot of discrimination like that in life. Yes, let's not make gender discrimination." Isp-8

Example 8: "Remember, women are very intelligent. Be aware of your intelligence and potential. Encourage people to think that woman can do and succeed whatever she demands and being female is not being a second-class person. Every woman can accomplish what she wants. Because we are the ones who will disseminate these ideas and views about woman in the society." (Isp-1)

Criticisms about gender roles, taken from the parts of stories, have emerged as a reflection of the perception and thought style, in favour of and prioritizing women.

\section{Language Code}

To collect data in this study, it was demanded from the participants to structure stories by using at least 10 of given 40 words. However, this category has been created to understand whether the selected and used words are in/outside of the language practices that can be used in the narrative technique. In this sense, understanding the meanings they have placed in their chosen words and whether they were used in a different semantic pattern, have been the subject of examination of this category. In the stories, we found some words and phrases, which were used differently from their first, well known and basic meanings and in some, original, not ordinary semantic structures. Thus, they revealed and outlined a broader perspective and gendered/sexist discourse:

Example 9: "We do not have a house holder or dominant breadwinner in our house because we have a family council." (Mlt-2)

The author of the text, which puts a house holder/breadwinner (a father implied) and family council in an opposing position, could express their point of view about the concept of family as a joint/universal by using the widest possibilities and opportunities of language. The participant has also introduced a democratic attitude by transforming the singular structure of the family/house head to a pluralistic element like a parliament. Thus, instead of directly expressing the democratic attitude, the meanings of the words given were extended with a careful attention. Again, in one of the stories titled 'Equality' (Isp-1); a student took initiative and out of the words given as 'science' and 'man', they used scientist (instead of science man, which is a common usage), reflecting directly as a way of thinking against sexism.

Example 10: "At the age of fifteen, two girls who are completely unaware of eachother... their lives are totally different ... The only thing they have in common is their gender and their future career choice ... they both want to become scientists when they grow up .... one of their biggest dreams is becoming a scientist, to be to make inventions." (Isp-1)

In this sense, language practice has taken place in this text as a reflection of the viewpoint of the participant in the context of sexism as well as conscious choices. This expanded meaning zone can be expressed as an important finding in terms that it implies 
the meaning that students attribute to the words. It can be said that the words provided to students, were used in a broader semantic pattern than in the traditional usage with values on them, and in different syntactic structures. Thus, we can say that students approached the issue of sexism and the structures related to it by using a language/discourse in a more creative and broader sense. The given words point to a different semantic situation in the emotional world of the students. They have made more careful choices about using the language when presenting their attitudes and have succeeded in giving this high level of attitude in narrative texts they created.

\section{Grammatical Constructions and Features}

In this section, it was investigated in which word or lexical way, the group structures with at least two components and morphological orientations were communicated. It is important to recognize the fact that these structures, formed in the syntax, include statements of judgment and which lexical structure was used for expressions of sexism and sexist perception. Additionally, another important element of investigation and discussion of this chapter is, identifying types of words used in sentences, and the values attached to them when they were used to refer women or men.

Examples:

“... my mom does a favour for us and brings pizza or hamburger to home. This is nice and beauty of her." (Mlt-2)

“.. the breadwinner/ house holder was father." (Mlt-3)

“... my mother looked at us with violence in her eyes.” (Mlt-6)

"Once upon a time, there was a man whom everybody admired his intelligence and wisdom. Additionally, he was man of his words (he was keeping his promises in all conditions) (Mlt-14)

"Their father was very good, honest, used to keep his promises and strong man like a real man." (Ist-2)

“... in this family everyone is equal and strong.” (İst-5)

“... the children in the orphanage who were men of their words (keeping their promises) were doing a few small things to newcomer.” (IST-9)

“... and the hardest tasks were given to Ayşegül." (IST-9)

“... Ayşegül ... had to deal with him, she was afraid, she was trying to be strong, but ..." (İst-9)

"Hi I'm Duru ... I want to be an employee like a man." (Ist-11) (like a man, or manly is used to mean 'properly or decently' in Turkish. And students also used in this meaning)

“... but his father told him that you are brave and strong." (Ist-13)

"There was constant violence in the house, she was under constant pressure from her brothers and father." (Isp.-1)

"The difficulty of being a woman ..." (Isp-1)

“... there are many women who have difficulties in life." (ISP-1) 
"... the founding boss stood up and hugged me with a mother's compassion." (ISP-4)

"... it is the people who show that women can be strong as well." "Men can be vulnerable, women can be courageous." (ISP-9)

"In this house the real man works" (Kon-3)

"Female cat could have been a victim of violence." (Adana-4)

The expressions in the texts such as beauty, nice, housework, domestic work, victim etc. were used either to refer women or as statements to describe women or their actions/deeds. Moreover, as can be seen in the examples, discourses such as; breadwinner/householder, courageous, brave, man were used by students as parts of masculine rhetoric. In this category of grammatical structures and properties, two noteworthy elements were reflected in the texts: Words and word groups such as power, strength, being strong, violence, business and man were reflected in the texts of students as a descriptive element of gender roles related to both men and women and as a structural element expressing them. Based on their intentions, perceptions and the discourse that they want to create, students used the given words as nouns or adjectives, or sometimes they converted them into forms to be able to use as adverbs. When we examine deeply these personal choices and usages, we can conclude that they are referring to or reflecting a sexist perception or a gendered discourse. In particular, the words like household, head of house/ authority of the house, brave, man etc. point directly to the presence of a masculine language or vocabulary, while words like tasks, errands, duties and violence were expressed in morphological structures in which the concept of woman was found. Nevertheless, expressions as power, courage etc. were used in the sentences where subject was either female or male, or they were even used without a gender attribution, in some morphemes where the concept of child was centred. In particular, some students used some of the given words which have adjectival value, as nouns with the concepts of woman, man or child. These kinds of special and personal usages give important hints about user's perception on gender. By analysing of deliberate choices of students, as; which words were used together with which structures that reflect a social gender and also, whether sexist words were used to imply woman or man; students' perceptions about gender and gender roles in society were revealed. The fact that some words were used differently from the general sexist references reveals both the sexist point of view and the different way of thinking and approaching of the user about this topic. Especially "....the children in the orphanage who were men of their words (keeping their promises) were doing a few small things to newcomers." (IST-9) They used the expression of 'being a man of his words' to mean 'keeping promises/hold on to promises in all conditions'. This attribution group, which refers to masculine language in all other texts, used to describe a positive feature/characteristic of children without gender references; by excluding the basic reference values of any sexist discourse. However, they used "man of his words" to mean keep promises in all conditions and never give up behaving like that. 
Examples:

"They give man's promises." (Mlt-2) ( $>$ if you are giving a man's promises, instead of just promising, that means you will keep it undoubtfully)

"Give me a man's promise" (Street fighting) (Siv-1)

"I know, I gave a man's promise" (Ist-13)

"The man was clever and also he was man of his words" (Mlt-14) (>keeping his promises in all conditions)

The morphological structures described above are used as deeds and nouns by different users living in different parts of the country. The words and phrases as; 'clever, being a man of his words, giving a man's promise' were used semantically in sentences in the context of gender roles designated for men. These expressions were used by the students as referring to the most important element in syntactic structures.

\section{Evidence on Vocabulary}

Vocabulary specificity research has been conducted in order to determine how the given words were expressed in syntactic structure, regarding the sentence emphasis, and which place they took in structural units of syntax and to identify their indicators about the views and attitudes of participants towards sexism. This clarity was expressed here through sentence emphasis, which is a stronger structure than individual emphasis of words, depending on the meaning expressed by sentences.

Examples:

“... there are many women who have difficulties in life." (ISP-1)

"In this house man enough works." (Kon-3) (Man enough, real man)

“... you will know rules, prohibitions and responsibilities of business life.” (Kon- 6)

Some of the selected words have been emphasized and highlighted as the most important element of the sentence. In most of the texts which were written differently from these, the words were used in the syntax as other emphasis elements. In order to be able to make sense of words or utterances in oral expressions, some structures similar to wording emphasis were rarely encountered in order to clarify a feeling or thought. This has been made possible by using exclamation marks and some elements of spoken language in writing; in this way clarity on vocabulary was provided.

Example: "Everyone will fulfil his responsibilities!" (Mlt.-10)

\section{Attitude Power}

In general, the attitude which is defined as a tendency that regulates feelings and behaviours related to events belonging directly to the individual. The structures that an individual develops attitudes, at the same time, have psychological meaning and manifest themselves in thoughts and subjective use of language. So, adverbs and adjectives that specify manner, quantity, quality and make descriptions in relation to the 
given words were examined in this context and such an analysis was done in order to determine the sexist views of the students who created texts.

Examples:

"Real man (man enough) must be strong." (Mlt-9)

“... Ayşegül (a female name) was trying to be strong." (Ist-7)

“... women can also be strong ... Men can be vulnerable, women can be brave." (Isp-9)

“... When a violent man was deported, he went like a real man." (Mlt-11)

"Because the child was man of his word." (Kon 1) (>the child was keeping his promises)

"Their father was honest, strong as a real man who was keeping his promises all the time" (Ist 2)

"Everyone should have been able to take over their work and be strong." (Ist-4)

"Everyone in this family is equal and strong." (Ist-5)

"When a newcomer comes to the orphanage, children who are men of their words" (>keeping their promises in all conditions) (Ist 9)

"There was a man, who was enjoying his job and doing it well. He behaved like a real man." (Ist-15)

As can be seen in the examples given, especially the words as; power, vulnerable and courage have been used by students to reflect attitudes of the users. Especially, references of power/strength to women were used as feature and manner that were thought to women should have in the context of their social gender roles. References to strength were used as masculine structure in a general discourse. It is used in the form of noun or adjective to describe men. As can be seen in the examples above taken from the texts of Ist-7 and Isp-9, the word of strong was used with women, and in their general atmosphere of these stories, women or girls were described as dominant characters or they were expected to be strong. This reflects the attitudes of these participants and their point of view and effort to clarify the relationship between women and strength. Again, in qualifiers and the nominalized adjectives; the expressions 'strength/power' were used to reflect a masculine discourse/ language, and to reinforce this, the phrases 'manly, like a man' were used in similar cases; one of these kinds of usages was exemplified above (Ist-2). However, the words; equality and work were used as general expressions for everyone, without specifying a gender; as can be seen in the examples above taken from texts, named as (Ist-4), (Ist-5).

\section{DISCUSSION}

At the beginning of the research, 40 words were provided to the participants to choose out of them and to write stories: the words that can allow participants to create sexist discourse, covert ones, and the ones that need background information about sexism and gender issues. In this context, the products produced by the students were classified according to certain categories. In the structures related to the linguistic form, intensely male or female expressions were observed and in terms of semantic constructs, students used them in a way to connate gendered discourse. The traditional uses of words have 
been observed in most of the stories that were expressed in the way they have place in the society. Particularly, the words and phrases as; making a man's promise, being a man of his word, man, manager, boss were used in texts in a way to reflect a traditional perspective of signifier and signified in the society. Expressions such as dinner, woman, family council were also used in this sense to mean basic gender roles. In this sense, it is seen that some of the students used the idioms, phrases and words in the frame of traditional usage values, expressing values of the taboo sexist discourse.

Different perspectives and open-mindedness produced, fostered or omitted in schools have significance for the different voices and identities present, the realities and ideals that can be expressed within classroom, and the students' conditions for developing different or opposing perspectives over dominant, prevailing ones (Liddicoat, 2009; Nelson, 2010; Simonsson \& Angervall, 2018). Similarly, in this study, there were also some cases where some of the words expressing sexism could be used outside of classical, expected or traditional meaning references. The words and phrases like; man, hold on to promises and courage were used not only as a language product under male supervision and dominance, but also used in sentences where female characters were the subjects of the actions and/or used as words representing women, by showing the perspectives of the students about gender issues and creating a gendered discourse. In this sense, we can conclude that language structures in men's sovereignty and dominance evolved into a language and discourse in which women were centralized. This shows that; the lexical structure, which were created and given meaning by masculine language, could be changed regarding meaning and point of view by the participants in their discourses. The language choices in the stories and the language that was built up accordingly did not only reflect the reality of the students but also their thinking processes.

It is also important to problematize what is underestimated, unnoticed, unmarked and passed without giving any attention; often seen as a sign of conforming to the norms and socio-cultural reality, and hinders developing perspective and identity over the accepted ones (Butler, 2011). In this context, we can infer that in this study, language drew a framework for the gendered perspective and opened up a field where many things can be observed, notably about cultural identity. These factors also have served as important source of data that give way to understand students' insight into sexism; which words were used with which type of structures, how they were used and in which context, which reference values were expected, thought and created by students. This has emerged in the texts as an important factor that elicits students' attitudes towards sexism.

Since discourses/texts have both social and cognitive aspects, in order to understand cultural perspectives and worldviews, it is needed to grasp how members of specific discourse communities construct, interpret and use language practices and discourses to achieve their goals and reflect their ideas and why they write them the way they do and their language competencies, to what extent they can express their socio-cultural values by using language effectively and on purpose (Bhatia, 2002). In this direction, we can evaluate one of the important findings/results of this research which is; even though the attempts made by some students, some stories could not manage to reflect their 
perspectives about gender issues, because of their inadequate competency in vocabulary and language use. This ambiguity and uncertainty have been included and discussed in findings part, since it also presents an important finding about students which is; this uncertainty was not caused by lack of gendered perspective but because of lack of language practices needed. As a result of the analyses made, some of the stories structured with chosen words neither revealed students' perspective about gender and gender roles in the society, nor they provided data about background knowledge of the participants.

Different perspectives whether produced or neglected have significance for conditions for voicing in the classroom and for what narratives and realities that can be expressed or not within the classroom, in their written productions and fictions (Simonsson \& Angervall, 2018). Accordingly, in this research, which aims to reveal the sexist/gendered ideas and viewpoint of the students by examining stories of the students and analysing the discourses of them, it was seen they used the words in a way that reflect a traditional perspective; and references and meaning attributed to them accordingly. The majority of them presented a sexist point of view in accordance with the traditional roles attained to genders by the society and culture. They created discourses that conform to general and traditional perspective about gender and gender roles in the society. As a conclusion, it is very important to determine what is problematized, recognized, highlighted and given importance and attention in educational process; since through these processes, culture and social context are created and conveyed to next generations, in other words, society's future is constructed and maintained.

\section{CONCLUSION}

Language is important vehicle of cultural or social values and identity (Karyolemou, 1994). Taking into consideration of this fact, we can evaluate the following conclusion of the study, which is; all the participants of the study academically bright students since all of them were identified as gifted and selected to get acceptance to attend BİLSEM- although they are at different ages, most of them showed through their discourses that they had traditional views about gender, conforming to the society's prevailing culture and values. Therefore, they employed the words in their stories accordingly. Regarding women characters, they were stuck with their domestic duties, as preparing 'meal' and running errands with all of their 'beauty' in their 'pink' and 'vulnerable' world. Men were drawn as characters that are 'strong', 'responsible' to 'provide' all the necessary conditions for the survival of family, reigning their homes and as 'powerful' images who could do everything properly and decently.

Taken together, the results showed that most of the participants have taboo ideas about gender roles which can be a signal for educators, faculties of education, teacher trainers, and educational policy-makers. Only a few of them were able to create and develop discourses which were opposing and alternative to the settled, prevailing and maintained traditional view underlining discriminative approach to gender issues in which roles of women and men described clearly and distinctively. Additionally, their relationship was described as not supportive one to each other but as successful on the condition that 
women and men fulfil their duties according to different 'gendered' expectations from each of them. In the few of the stories, students produced opposing discourses in which women were described as powerful 'main' characters, managing a house and/or business; however, women had to put a lot effort and cost much pain for them to get these privileges in life. In line with this inference, this research provides an exploratory analysis of the text-external features, which include both situational, contextual and socio-cognitive factors related to text/discourse construction; and the use, exploitation and interpretation of language, by members of the cultures under discussion (HerrandoRodrigo, 2015).

The most significant conclusion to be drawn from this study; researchers in education and education policy do not focus on identifying and analyzing student discourses, which would offer a lot of clues about the educational practices at schools, and they do not conduct studies about what kind of discourses are being tried to create and maintain through schooling which is a formal process of acculturation. Utilizing approaches as socio-linguistics and discourse analysis method would provide information about how values are conveyed, shaped and received through the discourses created in classrooms and at schools, by teachers, education programs and texts chosen to present students as material.

Regarding the very immediate outcomes of this study, it was revealed that students are being affected by prevailing socio-cultural perspectives and it seems they do not think about or question them. Really few of them can construct their own views and identities, this also shows the signs of lack of critical thinking and emphasis on it at schools. Taking into consideration of the fact that these children will shape our future and social identity, the issues of what kinds of discourses are being created at schools through programs and materials, especially texts, and to what extent teachers are aware of it, are very important. Identifying and observing linguistic attitudes is of primary significance not only for the understanding of linguistic behaviour in complex processes as codeswitching, borrowing and varieties etc. but also for the study of sociolinguistic communities in general and to understand social attitudes and behaviour (Karyolemou, 1994) Therefore, this study will open doors for other researchers who are interested in socio-linguistics studies in order to identify attitudes, perspectives and ideas of students towards gender issues and roles.

Language is a set of complex, organized systems that operate in concert with a great harmony to fulfil an intention and/or action (Krauss \& Chiu, 1998). A particular act of speaking can be analysed and described in its relation to any of these systems (Miller, 1975); and all these analyses can have significance to understand and explain social behaviour. By using language we actually do many things; such as proposing, asserting, rejecting, accepting or disseminating an idea, trying to attract supporters for it or trying to effect people in desired way or persuading them towards a certain view. Reflecting on already discussed together with conclusions made through this study, it seems even more crucial than ever before, to consider and identify cultural values that schools offers and students carry, and their sexist views and taboo gendered ideas-if any-. In this way this 
study will be a standpoint to start, discuss and approach critically how these important socio-cultural issues are taken into consideration and managed in educational process.

\section{RECOMMENDATIONS}

Limitation of this study is its length, as number of gifted students from which we collected data was limited, in 6 provinces of Turkey, so results cannot be generalized since socio-cultural background in which students were grown up are so diverse. More time and more gifted students from different geographical areas may have offered a larger range of data about different identities and socio-cultural contexts.

Another limitation was that the study focused so closely on gifted students. So if this kind of research could be conducted in all grades; in primary, secondary and high school periods, data would be obtained horizontally and vertically. Therefore, gradual process of developing and shaping students' way of thinking, perspectives and ideas at schooling can be observed and intervened in, if it seems necessary.

This study shows that, it should be paid attention about what kind of discourses and perspectives teachers, as mentors and role models, create and present to students in classrooms through their suggestions, teaching and approaches. Additionally, education programs should be prepared and text materials should be chosen accordingly by taking into consideration of the fact that they have effect to create discourse, ideology, culture and other social dynamics of a society, as students shape the future and they are the ones who will convey culture, ethics, and desired values that we want to prevail and maintain, free from gender discriminations and taboo ideas of gender roles. Accordingly, providing such values and cultural codes through direct and indirect instructions to students; and teachers' being aware of this fact, need to be considered as priorities for all educational organizations and policy makers

\section{REFERENCES}

Altıntaş, İ. N. (2016). Values that children aged between 9-11 acquire from cartoons and animation and their modeling behaviors. Route Educational and Social Science Journal, 3 (2), 316-335.

Bakhtin, M. M. (1981). The Dialogic imagination (C. Emerson \& M. Holquist, Trans.). Austin: University of Texas

Bandura, A. (1977). Social learning theory. New Jersey: Prentice-Hall, Inc. Englewood Cliffs.

Bhatia, V. (2002). Applied genre analysis: a multi-perspective model. Ibérica, 4(1), 319.

Bilgin, N. (2014). Sosyal bilimlerde içerik analizi, teknikler ve örnek çalışmalar [Content analysis in social sciences, techniques and studies]. Ankara: Siyasal

Butler, J. (2011). Bodies that matter: On the discursive limits of "sex." Routledge Classics. Abingdon, Oxon; New York, NY: Routledge.

Cameron, D. \& Kulick, D. (2003). Language and sexuality. Cambridge: Cambridge University Press. 
Çil, B. (2005). İstatistik. Ankara: Detay

Florio-Ruane, S. \& Morrell, E. (2012). Discourse analysis: conversation. In M. H. Mallette and N. K. Duke (Eds.) Literacy Research Methodologies 46-61. London: Guilford Press.

Fraenkel, J. R. \& Wallen, N. E. (2000). How to design and evaluate research in education. New York: McGraw-Hill.

Gee, J. P. (2008). Social linguistics and literacies: Ideology in discourses. New York: Routledge.

Holmes, J. \& Marra, M. (2010). Femininity, feminism and gendered discourse. In J. Holmes and M. Marra (eds) Femininity, Feminism and Gendered Discourse: A Selected and Edited Collection of Papers from the Fifth International Language and Gender Association Conference (IGALA5). UK: Cambridge Scholars Publishing

Herrando-Rodrigo, I. (2015). Attitudes and discourse: Spanish practitioners' and undergraduates' survey results. Profile issues in Teachers' Professional Development, $17(1), 55-72$.

Karyolemou, M. (1994). Linguistic attitudes and metalinguistic discourse: An investigation in the Cypriot press. In:Irene Philippaki-Warburton, Katerina Nikolaidis, and Maria Sifianou (eds.) Themes in Greek Linguistics. Papers of the First International Congress on the Greek Language. Amsterdam/Philadelphia: John Benjamins, 253-259

Kilmen, S. (2015). Eğitim araştırmaları için SPSS uygulamalı istatistik [SPSS based statistics for educational researches]. Ankara: Edge

Krauss, R. M., \& Chiu, C.-Y. (1998). Language and social behavior. In D. T. Gilbert, S. T. Fiske, \& G. Lindzey (Eds.), The handbook of social psychology, 41-88. New York, NY, US: McGraw-Hill.

Kulick, D. (2006) No. In D. Cameron and D. Kulick (eds.) The Language and sexuality reader, 285-98. New York: Routledge

Lakoff, R. (1975). Language and women's place. New York, NY: Harper \& Row.

Levon, E. \& Mendes, R. B. (2016) (eds). Language, sexuality, and power: studies in intersectional sociolinguistics. Oxford: Oxford University Press.

Liddicoat, A. J. (2009) Sexual identity as linguistic failure: trajectories of interaction in the heteronormative language classroom. Journal of Language, Identity and Education, 8(2-3), 191-202.

Milani, T. M. (ed.) (2015). Language and masculinities: performances, intersections, dislocations. New York: Routledge.

Miles, M. B. \& Huberman A. M. (1994). An expanded sourcebook: Qualitative data analysis. CA: Sage Publications. 
Miller, G. A. (1975). Psychology, language and levels of communication. In A. Silverstein (ed.), Human communication:Theories and experiments. Hillsdale, NJ: Erlbaum

Nash, R. (1990). Bourdieu on education and social and cultural reproduction. British Journal of Sociology of Education, 11 (4), 431-447

Nelson, C. D. (2010) A gay immigrant student's perspective: unspeakable acts in the language class. TESOL Quarterly, 44(3), 441-64.

Seçer, İ. (2017). SPSS ve LISREL ile pratik veri analizi [Practical data analysis through SPSS and LISREL]. Ankara: Anı

Simonsson, A. \& Angervall, P. (2018). Girls' sexual subjectivity in a secondary language classroom. Gender and Language, 12.2.2018, 218-241.

Sullivan, A. (2002). Bourdieu and education: How useful is Bourdieu's theory for researchers? The Netherlands' Journal of Social Sciences, 38 (2), 144-166.

Sullivan F.R., Kapur, M., Madden, S. \& Shipe, S. (2015). Exploring the role of 'gendered' discourse styles in online science discussions. International Journal of Science Education, 37 (3), 484-504.

Ochs, E. (1992). Indexing gender. In A. Duranti and C. Goodwin (eds.) Rethinking context: language as an interactive phenomenon, 335-58. Cambridge: Cambridge University Press.

Özdemir, E. (2014). Tarama yöntemi [Reviewing method]. In M. Metin (ed.) Ĕgitimde bilimsel araştırma yöntemleri [Scientific research methods in education]. Ankara: Pegem Yayınc1lık

Poplack, S. (1987). Contrasting patterns of code-switching in two communities. Proceeding of the $4^{\text {th }}$ Nortic Symposium on Bilingualism, 51-77. Uppsala

Poplack, S. (1989). Statut de langue et accomodation langagiere le long d'une frontier linguistique. In R. Mougeon \& E. Beniak (eds.) Le français canadien pale hors Quebec: aperçu sociolinguistique, 127-151. Quebec Presses Universitaires de Laval.

Tannen, D. (1994). Gender and discourse. New York, NY: Oxford University Press.

Wolfram, W. (1986). Good data on bad situation: Eliciting Vernacular Structures. In J. Fisherman, A. Tabouret-Keller, M. Clyne, Bh. Krishnamurti \& M. Abdulaziz (eds.) The Ferusonian impact, Vol 2, 3-22. Berlin, New York, Amsterdam: Mouton de Gruyter. 